\title{
Detection of SARS-CoV-2 using high-throughput PCR
}

\author{
Saakshi Jalali, Vikas Kumar Patel, Ajit Sapre, Santanu Dasgupta, Venkatesh Prasad and Bhaskar Bhadra* \\ Synthetic Biology group, Reliance Corporate Park, Reliance Industries Limited, Navi Mumbai 40070I, India \\ *, corresponding author, e-mail: Bhaskar.Bhadra@ril.com, Phone: 009l 2244750885
}

\begin{abstract}
During an epidemic identification of infected individuals, quarantining them, and thereby protecting healthy individuals from infection will not only help to flatten the curve but will also help medical professional to treat the epidemic efficiently. Countries with high-density population require sensitive and accurate screening method, which could be done without a sophisticated laboratory, broadens the scope of control and surveillance. High-throughput screening method without expensive instrumentation is the desirable. For the SARS-CoV-2 pandemic qRTPCR emerges as a gold standard for identification of infection, however, infrastructure required for this assay is at high-demand and not abundant. Therefore, we proposed a high-throughput PCR based sensitive method which provides an opportunity to facilitate detection of virus without sophisticated diagnostic infrastructure.
\end{abstract}

\section{Introduction:}

On $30^{\text {th }}$ December 2019 China reported a serious viral pneumonia disease outbreak and the causative agent was identified as a novel coronavirus named as 'SARS-CoV-2' (Wu et al., 2020). Over the past few months, this newly discovered coronavirus has spread globally and caused more than 50,000 deaths The coronavirus disease (commonly known as COVID-19) being highly contagious has rapidly spread from human to human across the world, through droplet infection. Over last three months more than one million people are infected by the virus and numbers are growing alarmingly. Last month, this disease has been declared a pandemic by the World Health Organization (WHO). With a rapid increase of demand of health-care facilities, COVID 19 pandemic is straining health care systems worldwide (Weissman, 2020). Even the developed countries with excellent health care systems are overstretched and unable to operate effectively due to unprecedented inflow of patients every day. This disease poses a significant threat to the counties with comparatively weaker healthcare infrastructure. Considering population density of India (I.3 billion), the existing health-care facilities are certainly inadequate to fight this pandemic. Therefore, preventive measures through social distancing, isolation of infected patients and lockdown is the sensible option that is being pursued in India to combat community transmission of COVIDI9.

\section{Detect and Protect:}

Globally, this extraordinary situation demands tailored solutions for COVID 19 diagnosis, immunization and treatment. Considering the communicable nature of the disease it is a prerequisite to develop an efficient and robust screening methodology for COVID I9 (Hellewell et al., 2020) infected people to curb its spread. Currently, the number of tests for its detection in India is comparatively less than other countries like Singapore, South Korea, Hong Kong, etc. Various companies have come up with qRT-PCR and antibody-based diagnosis kits. Such methods 
Sample collection

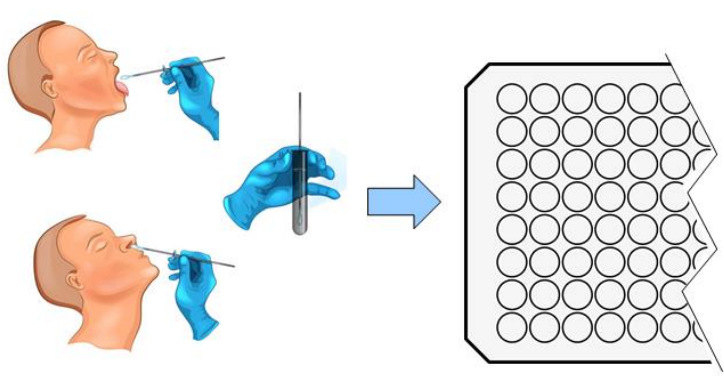

96 well PCR

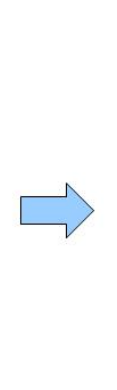

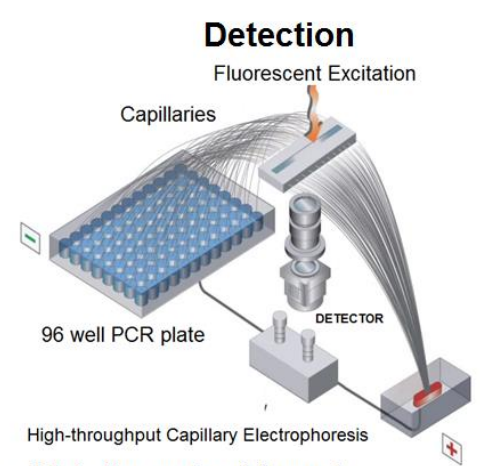

Step 1: Extraction of RNA from Swab, and cDNA preparation in a high-throughput format

Step 2: identification of specific PCR amplification of the specific cDNA (50 - 100 nucleotide region)

Step 3: Capillary electrophoresis and detection of amplicon specific to SARS-Cov-2

Figure I: Schematic diagram showing a process flow for PCR based early detection of SARS-Cov-2 in throat/ nasal swab samples

are not cost-efficient and require expensive infrastructural facilities. As PCR machines are more abundant than $\mathrm{qRT}-\mathrm{PCR}$ machines in various universities, diagnostic testing centers, and colleges, the need of the hour is to utilize the available resources for expanding the diagnostics capacity. Therefore, development of a PCR based detection system for SARS-Cov-2 will improve throughput of sample screening in small towns and villages of India. Presently, only people with overt symptoms are getting tested. Since, many cases of COVID 19 are mild or asymptomatic, it's not known how many people have been infected, and we may never know how many new cases will arise because of existing lag in testing. Presently, only people with overt symptoms are getting tested. Since, many cases of COVID-19 are mild or asymptomatic, especially in younger population, an early detection will minimize occurrence of community spread.

\section{High-throughput PCR based detection:}

In the current report, we are highlighting a PCR based COVID 19 detection strategy. Such tests use an approach to spot the presence or absence of the virus's genetic material in the collected samples. This PCR technique amplifies small stretch of viral genome using custom-designed "primers" at a high stringency condition. (a) The sample is collected from the oral/nasal cavity of suspect patients using a synthetic fiber swab with plastic shafts; (b) transit the swabs from the collection point to the testing point should be done in tubes containing viral transport media; (c) high-throughput RNA extraction from the swab samples; (d) cDNA synthesis of the extracted RNA in 96 well plate format; (e) 96 well plate PCR using selective primers; ( $f$ ) capillary electrophoresis of the 96 well PCR plate to identify PCR products in positive samples. Figure I below depicts a schematic of the overall procedure for COVID 19 detection using PCR technology.

\section{Reagents and kits:}

As explained in Fig. I, the first step is to collect the sample in swab from the throat or nasal cavity of individuals using viral transport media (TMMEDIA, India). The kit has one sterile flocked collection swab and a tube of Viral Transport from the place of collection to testing laboratory. Buffers and antibiotics content of the medium is recommended by CDC and $\mathrm{WHO}$ which ensure violability of the coronavirus during transport. The next step is to extract RNA from this solution in a 96 well-plate format and any of the kits such as RNA extraction kits such as PureLink $^{\mathrm{TM}}$ Pro 96 total RNA Purification Kit (Thermo Fischer), E-Z 96® Total RNA Kit (Omega Bio-Tek); Mag-Bind® Total RNA 96 Kit (Omega Bio-Tek); 96-well purification of total RNA from cells (Qiagen) could be used. The third step is RT PCR of the extracted RNA in a 96 well format and SuperScript ${ }^{\mathrm{TM}}$ III First-Strand Synthesis System (ThermoFischer) or 
TurboCapture 96 mRNA kit (Qiagen) could be used. The forth step is to run a 96 well PCR using the designed RIL-CoVID primers (Table I) and 2x QIAGEN Multiplex PCR Master Mix (Qiagen) or AmplyMAX TM Multiplex PCR Master (Canvaxbiotech). PCR machines with 96 well thermal block of ThermoFischer, Biorad, or any other model could be used for PCR amplification. Detection of desired PCR products in 96 well plate could be done using 7100 CE System (Agilent) or Capillary Electrophoresis (SCIEX) as detailed in Figure I.

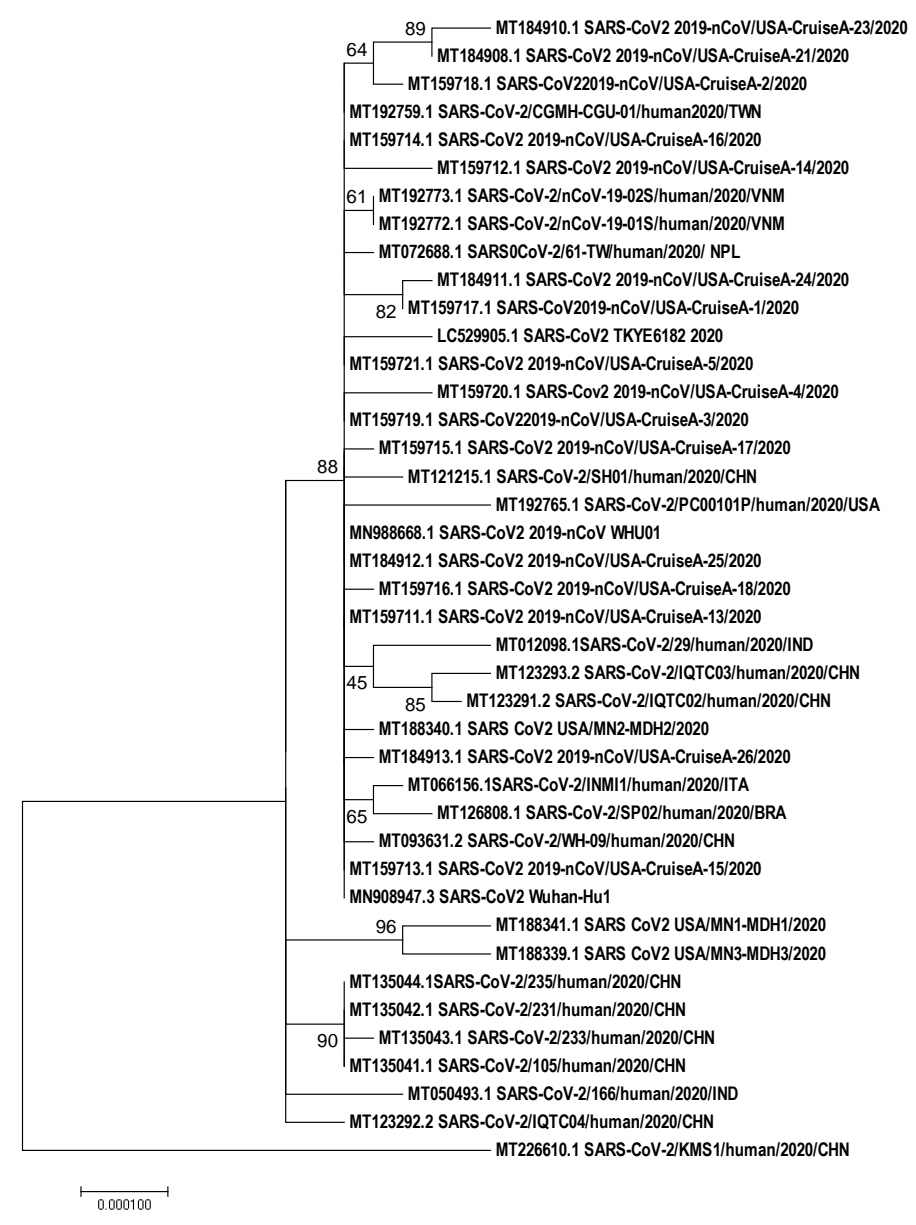

Figure 2: Neighbour joining phylogenetic tree derived using 4 I genome of SARS - CoV2 showing very high similarity between genomes of the virus sequenced in different countries. The tree was constructed with MEGA 7.0 software package and used the bootstrap value for 500 replications. Genome of MT2266/O SARS-CoV-2/ KMSI/CHN was used to root the tree. The bar represents I base changes in 10000 nucleotides.

\section{Designing of primers for SARS-CoV-2:}

Genome of 4 I variants of SARS - CoV-2 has been downloaded from NCBI and aligned using Multiple Sequence Alignment (MSA) tool for phylogenetic analysis using MEGA 3.0 software package (Kumar et al., 2016). The phylogenetic tree constructed using 28.5 KB consensus DNA region indicated a high degree of similarities among the genomes of the various SARS-CoV-2 sequences at different part of the world (Figure 2). We have identified some conserved regions from MSA alignment file and have designed PCR primers using an in-house algorithm. A set of 100 pairs of oligos were then subjected to similarity searches against other viral genomes and human genome. Finally, the primers which showed less than $50 \%$ homology in human genome and less than $70 \%$ homology with other viral genomes in NR database were shortlisted. Table I has list of primers and probes which can be used for PCR amplification and hybridization probes. The DNA fragments amplified using the PCR primers were identified as genes (partial) for surface glycoproteins, envelope protein 'E", membrane glycoprotein ' $M$ ', ORF3a protein and nucleocapsid phosphoprotein (Table I). Except ORF3a, all these proteins fall in the category of structural proteins which plays an important role in building up the capsid of the virus.

\section{Community infection assay:}

The PCR method discussed here could also be used for scoring stage -3 or community screening of infection. Pooled cDNA mix of $10-12$ samples could be added in each well of PCR plate. After PCR amplification capillary electrophoresis of each well will identify the well containing infected samples. During stage I and stage 2 of an epidemic majority of samples tested (95\%) are negative; therefore, a method that does not load the, qRT PCR is desirable. As it will negatively impact the throughput of screening. The process described here (Figure 3) will help in identifying uninfected sample pool and thereby requirement of $\mathrm{qRT}$ PCR based high value and efficient systems could 
be employed to the focused samples only as a confirmatory test. This method will also help in driving a super-high-throughput assay to score community transmission with a statistically validated model ( $\mathrm{Hu}$ et al., 2013) for heavy density population such as slum-dweller in Mumbai or migrant workers.

\section{Conclusion:}

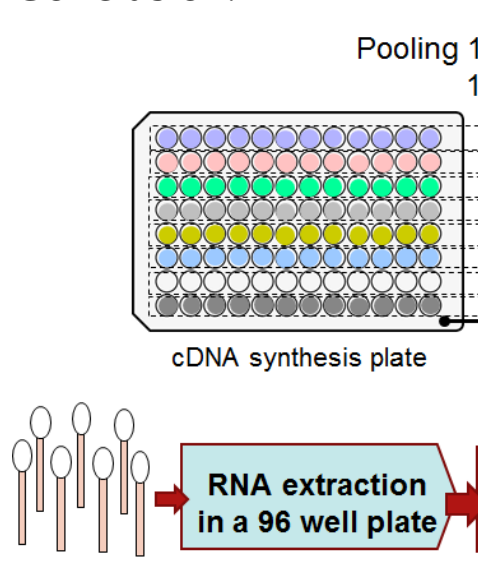

Swabs

2 samples in
well
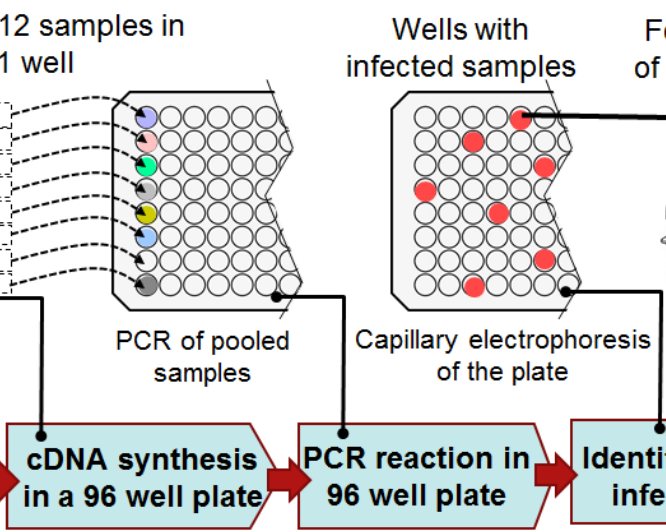

cDNA synthesis in a 96 well plate

A, Virus marker 1; B, Virus marker 2; C, Virus marker 1 and 2

$D$, Test samples containing virus (pooled samples from a well of PCR plate) E, Test samples without virus (pooled samples from a well of PCR plate) throughput electrophoresis, simple agarose gel loading with multichannel pipette could also be used. Such manual intervention may reduce throughput, however, that can be partially overcome by the pooled sample analysis pipeline described in Figure 3. Kits and methods which work best for the proposed pipeline are derived by talking to more than 100 scientists working

Figure 3: Schematic representation of super-high-throughput screening for COVID 19 infection using pooled-sample analysis. The method proposed here enable 1000 sample analysis in one shot for stage-3 or community infection scoring.

We hypothesized that in infected individuals the abundance of the mRNAs of these genes (listed in table I) will be at the higher number, and therefore, nucleic acid-based detection system will be more efficient to identify early infection. On the other hand, IgG or IgM based immunological principles may miss the window of early detection as the titer of these proteins in the blood may take $4-10$ days post infection (asymptomatic stage). Therefore, we have focused on designing probes and primers which will help us detecting early infection ( $\mathrm{I}-4$ days). In the table I we have also listed probes which could be used for in - situ hybridization assay (Huber et al., 2018). The stringency of the forward and reverse oligonucleotides/ PCR primers were checked in-silico for potential secondary structure formation and primer dimerization characteristics using various in silico PCR tools available online. In the overall pipeline of the process we have added capillary electrophoresis to reduce time lag and throughput. However, in absence of such high- across different labs of India. However, kits with similar specifications could be used based on availability at different countries.

Overall, the method of screening is not only efficient but also could be optimized to high- / super - high - throughput assay. This method will also help decentralization of sample testing with minimal or no modification of existing infrastructure in universities, institutes or diagnostic centers across the country. We believe that our proposed pipeline of PCR based sample screening will reduce dependency of $q R T$ PCR machines and reagents and will enable large scale community screening to combat spread of the infection by restricting it to stage 2 of the epidemic. 
Table I: List of RIL-COVID primers and probes for designing PCR or FISH based approach for detection of virus

\begin{tabular}{|c|c|c|c|c|c|}
\hline S.No & Primer Sequence & $\begin{array}{l}\text { Primer } \\
\text { Length }\end{array}$ & $\begin{array}{l}\text { PCR } \\
\text { product }\end{array}$ & Target gene Name & Gene details \\
\hline $\mathbf{I}$ & $\begin{array}{l}\text { Probe: } \\
\text { ACAGTTTATGATCCTTTGCAAC }\end{array}$ & 22 & - & Surface glycoprotein & $\begin{array}{l}\text { GenBank ID: QIK50448.I } \\
\text { Coordinates: 2I563-25384 } \\
\text { Gene Length: } 382 \text { I }\end{array}$ \\
\hline 2 & PF: TCGGAAGAGACAGGTACGTT & 20 & & \multirow{3}{*}{ Envelope protein } & \multirow{3}{*}{$\begin{array}{l}\text { GenBank ID: QIO04369.I } \\
\text { Coordinates: } 26245-26472 \\
\text { Gene Length: } 227 \text { bp }\end{array}$} \\
\hline 3 & RP: CAATATTGCAGCAGTACGCA & 20 & 124 & & \\
\hline 4 & Probe: CATCCTTACTGCGCTTCGAT & 20 & - & & \\
\hline 5 & PF: CTGACCAGACCGCTTCTAG & 19 & \multirow{2}{*}{146} & \multirow{3}{*}{ Membrane glycoprotein 'M' } & \multirow{3}{*}{$\begin{array}{l}\text { GenBank ID: QIO04370.I } \\
\text { Coordinates: } 26523-27191 \\
\text { Gene Length: } 668 \text { bp }\end{array}$} \\
\hline 6 & RP: GAAAGCGTTCGTGATGTAGC & 20 & & & \\
\hline 7 & Probe: GACCTGCCTAAAGAAATCACT & 21 & - & & \\
\hline 8 & PF: CAAGCTTTCGGCAGACGTG & 19 & \multirow{2}{*}{155} & \multirow{9}{*}{$\begin{array}{l}\text { Nucleocapsid } \\
\text { phosphoprotein }\end{array}$} & \multirow{9}{*}{$\begin{array}{l}\text { GenBank ID: QIO04374.I } \\
\text { Coordinates: } 28274-29533 \\
\text { Gene Length: } 1259 \text { bp }\end{array}$} \\
\hline 9 & RP: TCCATGCCAATGCGCGAC & 18 & & & \\
\hline 10 & Probe: GCTTCAGCGTTCTTCGGAA & 19 & - & & \\
\hline I I & FP: TAATGGACCCCAAAATCAGC & 20 & \multirow{2}{*}{89} & & \\
\hline 12 & RP: TGCGTTCTCCATTCTGGTTA & 20 & & & \\
\hline 13 & FP: GAACTGATTACAAACATTGG & 20 & \multirow{2}{*}{87} & & \\
\hline 14 & RP: CTTCCATGCCAATGCGCGACA & 21 & & & \\
\hline 15 & FP: TGCAACTGAGGGAGCCTTGA & 20 & \multirow{2}{*}{92} & & \\
\hline 16 & RP: CTTGAGGAAGTTGTAGCACG & 20 & & & \\
\hline
\end{tabular}

\section{References:}

Wu D, Wu T, Qun Liu Q, Yang Z.. SARS-CoV-2 outbreak: what we know. Int J Infectious Diseases. (in press) doi: https://doi.org//0.1016/j.ijid.2020.03.004.

Weissman GE, Crane-Droesch A, Chivers C, et al. Locally informed simulation to predict hospital capacity needs during the COVID-19 pandemic. Ann Internal Medicine 2020; (in press) doi: https://doi.org/I0.7326/M20-I260

Hellewell J, Abbott S, Gimma A, Bosse NI, Jarvis Cl, Russell TW, Munday JD, Kucharski AJ,

Edmunds WJ, Funk S, Eggo RM. Feasibility of controlling COVID-19 outbreaks by isolation of cases and contacts. The Lancet 2020; 8 (4), 488-496.

Rabi FA, Al Zoubi MS, Kasasbeh GA, Salameh DM, Al-Nasser AD. SARS-CoV-2 and

Coronavirus Disease 2019: What We Know So Far. Pathogens. 2020 9(3). doi: 10.3390/pathogens903023I.

Kumar S, Stecher G, Tamura K. (2016); MEGA7: Molecular evolutionary genetics analysis version 7.0 for bigger datasets. Molecular Biology and Evolution 2016; 33:1870-1874

$\mathrm{Hu} \mathrm{H}$, Nigmatulina K, Eckhoff P. The scaling of contact rates with population density for the infectious disease model. Mathamatical Bioscience 2013; 244 (2); 125-I34

Huber L,Voith von Voithenberg L, Kaigala GV. Fluorescence in situ hybridization (FISH): History, limitations and what to expect from micro-scale FISH? Micro and Nano- Engineering 2018; I, I5 - 24 